\title{
Patient-reported outcome measures on intake of nutrition drink for nutritional supplements after periodontal surgery
}

\author{
Hyeong-Seok Kim¹, In-Woo Cho', Hyun-Seung Shin', Jung-Chul Park ${ }^{1,2 *}$ \\ 'Department of Periodontology, College of Dentistry, Dankook University, Cheonan, Republic of Korea \\ ${ }^{2}$ Eastman Dental Institute, UCL, London, UK
}

Purpose: Patients usually suffer from pain and discomfort after oral surgery and their consumption of food is severely affected. Accordingly, the patients' quality of life reduce significantly. The aim of this study was to analyze patient satisfaction on the nutritional supplement drinks following periodontal surgery. Materials and Methods: Total 90 patients who underwent periodontal surgery were recruited and commercially available nutritional drinks were provided. Group I received two bottles per each meal for 2 days, Group II had one bottle per each meal for 3 days, and Group III had no drinks. The survey for the patient-reported outcome measures (PROMs) were given at the next visit for the removal of sutures. Results: The result of PROMs showed the nutrition drink was easy to intake, appeared to help the healing and can be a satisfying supplement for the meals. Conclusion: Nutritional drinks appeared to help the healing after periodontal surgeries and supported the food intake. Also, it was helpful for the patients in nutritional supply and psychological stability. (J Dent Rehabil Appl Sci 2016;32(3):176-83)

Key words: periodontal surgery; nutritional supplements; PROMs; wound healing

\begin{abstract}
서론
생명공학 기술의 발전에 맞춰 단순히 영양보충만을 추 구하던 식품업계도 기능성 식품을 통한 질병의 예방 또 는 치료를 도모하고 있다. 이들의 지속적인 의료 시장 참 여 확대에 따라 전반적인 기능성 식품 관련 기술력 향상 과 적극적인 마케팅으로 시장규모를 확장시키는 전기가 마련될 것으로 기대되고 있다. 이와 동시에 의료영역에서 도 환자 삶의 질 개선은 물론 치유의 촉진 및 보조를 위해 수술 전후 환자의 영양섭취에 대해 많은 관심이 증가하 고 있으며 특수의료용도용 기능성 식품을 통하여 술 후 식사가 어려운 환자의 영양보충에 도움을 주려는 시도가 주목 받고 있다. ${ }^{1-5}$
\end{abstract}

${ }^{*}$ Correspondence to: Jung-Chul Park

Assistant Professor, Department of Periodontology, College of Dentistry, Dankook University, 119 Dandae-ro, Dongnam-gu, Cheonan, 31116, Republic of Korea Tel: +82-41-550-0261, Fax: +82-303-3442-7364, E-mail: jcp@dent.dku.edu Received: August 19, 2016/Last Revision: September 12, 2016/Accepted: September 13, 2016
치주 질환은 치주조직의 만성적, 감염성 질환으로 성 인들의 치아 발거의 가장 주요한 원인으로 작용하고 있 고, ${ }^{6,7}$ 유병율이 최근 30 년간 계속 증가되는 양상을 나타 내며 치주 치료 보험 청구가 다빈도로 이루어지고 있는 실정이다. ${ }^{8}$ 치주 치료는 대표적으로 스케일링이나 치근 활택술과 같은 비외과적 치료 및 치은판막소파술과 같은 외과적 치료로 대별되는데, 이 중 외과적 치료의 경우 심 한 술 후 불편감 ${ }^{9}$ ㅘ 치아 동요도 증가 ${ }^{10,11}$ 를 야기하여 술 후 환자 삶의 질이 현저히 감소하는 것으로 알려져 있다. 또한 술 후 해당 술식 부위의 통증 ${ }^{9}$ 과 불편함으로 인하여 제대로 된 식사가 힘들며 따라서 적절한 영양 섭취가 불 가능한 것으로 선행연구를 통해 규명되었다. ${ }^{5}$

환자가 느끼는 수술 전과 후의 만족도는 삶의 질과 관

Copyright@ 2016 The Korean Academy of Stomatognathic Function and Occlusion. (c) It is identical to Creative Commons Non-Commercial License. 
련하여 치과 영역에 있어 많은 주목을 받고 있으며 환 자의 느낌, 증상, 인식은 양질의 치료 결과에 대한 추 후 정보가 된다. 이러한 분석을 위해 patient-reported outcome (PRO)이 최근 많이 활용되는데 이 분석은 환 자의 치료 결과에 관해 임상가 또는 다른 사람의 해석 없 이 환자가 직접 자신의 건강, 삶의 질, 치료와 연관된 기 능 상태를 보고하는 방식으로 최근 각광받는 분석법이 다. ${ }^{12-14}$ 본 연구에서 활용한 분석법인 patient-reported outcome measures (PROMs)는 환자의 기능적 상태, 건 강, 증상, 사회활동, 불안함, 불편감 등에 대하여 술자가 아닌 환자가 직접 자신의 만족도에 대해 측정하는 것이 다. 이는 의사 결정 중심에 환자를 배치함으로써 삶의 질 과 안정성을 증진시킬 뿐만 아니라 의료 변혁을 위한 가 능성을 인정받아 임상 연구를 넘어서서 영역을 확장하는 근거가 되고 있다. ${ }^{15}$

저자들의 선행연구에서 영양음료를 섭취한 일부 환자 들 중 과도한 포만감을 호소한 경우가 있었다. ${ }^{5}$ 이에 영 양음료 섭취에 대한 환자 만족도를 극대화 하고 규격화 된 영양음료 섭취 횟수와 양을 수립하며 또한 영양음료 비섭취 환자군 대비 섭취군의 실제 만족도를 $\mathrm{PROMs}$ 에 근거하여 분석해야 할 필요성이 대두 되었다. 이에 본 연 구에서는 외과적 치주 치료 수술 후 일정 치유 기간 동안 기존에 시판되고 있는 영양음료를 임의의 섭취법에 따라 2개의 실험군으로 나누어 마시게 하고 영양음료를 마시 지 않는 대조군을 설정하여 영양음료 복용에 대한 환자 의 만족도를 PROMs를 통하여 분석하였다.

\section{연구 재료 및 방법}

\section{1. 연구 재료}

1) 피험자

2016년 2월부터 2016년 4월까지의 기간 동안 단국대 학교 치과대학 부속 치과병원 치주과에서 외과적 치주 치료(치은판막소파술, 발치, 임플란트)수술 예정 환자 중
본 임상시험에 참여할 것을 자발적으로 서면 동의한 환 자를 대상으로 진행하였다(DUDH IRB 2015-12-006). 총 90 명의 환자를 다음의 그룹 중 하나에 무작위로 배정 하였다(Table 1).

영양음료의 양과 섭취방법에 따른 군 분류는 아래와 같았다.

*실험군 - Group 1, 2: 수술 후 10-14일 간 섭취횟수에 따라 영양음료 섭취

<실험 1 군> 수술 직후 2 일 간 1 회 2 캔씩 총 10 캔 섭취 $(\mathrm{N}=30)$ <실험 2군> 수술 직후 4일 간 1회 1캔씩 총 10 캔 섭취 $(\mathrm{N}=30)$

*대조군 - No drink: 수술 후 영양음료 섭취를 하지 않 음 $(\mathrm{N}=30)$

제외기준은 다음과 같다.

(1) 내원 이전 3 개월 이내에, 다른 임상시험약물을 투여 받은 경험이 있는 환자

(2) 기타 임상의의 판단에 적합하지 않다고 판단되는 환자

- 조절되지 않는 고혈압이나 조절되지 않는 당뇨와 같은 전신 질환을 가진 자

- 신장 질환을 가진 자

- 임신한 여성

- 최근 1 개월 이내 항생제를 복용한 경험이 있는 자

- 최근 6개월 이내 예방적 치과 치료 외의 치주 치 료를 받은 자

- 구강 내 연조직에 심각한 병적 소견을 보이는 자

2) 영양음료

본 연구에선 선행 연구를 통해 그 임상적 효능을 검증 한 바 있는 영양음료(뉴케어 ${ }^{\circledR}$, Daesang, Seoul, Korea)가 사용되었다. ${ }^{5}$

Table 1. Demographic information

\begin{tabular}{|c|c|c|c|c|c|c|c|}
\hline & Age \pm SD & Gender $(\mathrm{M}(\mathrm{F}))$ & Flap operation & Extraction & Implant & Advanced surgery & Sum \\
\hline Group 1 & $53.57 \pm 8.46$ & $15(15)$ & 7 & 4 & 11 & 8 & 30 \\
\hline Group 2 & $53 \pm 11.12$ & $11(19)$ & 12 & 4 & 6 & 8 & 30 \\
\hline No drink & $48.77 \pm 10.68$ & $14(16)$ & 12 & 2 & 7 & 9 & 30 \\
\hline
\end{tabular}

SD, standard deviations; $\mathrm{M}$, male; F, female. 


\section{Patient-reported outcome measure (PROMs)}

설문지는 기존 연구들을 참고하여 영양음료 섭취 후의 만족감을 조사하기 위한 본 연구에 맞게 저자가 직접 새 로운 항목들을 구성하였다. 설문항목은 실험군은 총 18 항목(객관식 16문항, 주관식 2문항)이였고 대조군은 총 10 항목(객관식 8 문항, 주관식 2문항)이였다. 설문지 작 성은 외과적 치주 치료(치은판막소파술, 발치, 임플란트) 수술 후 봉합사 제거 때 시행하였다. 각 문항에 대한 응 답 결과는 SPSS 12.0 통계 패키지를 활용하여, 기술통계 분석(descriptive analysis)를 이용하여 분석하였다.

\section{결과}

\section{1. 술 후 환자 불편감}

설문지 분석 결과, 실험군과 대조군에 있어서 술 후 식 사 불편감 정도에 대해 물어보는 항목에서는 식사 하는
데 조금 불편함이 가장 많았다라는 답변이 $32.2 \%$ 로 가 장 많았다(Table 2). 그 이유로는 수술 한 부위가 아프다 는 답변이 $45.9 \%$ 로 가장 많았다(Table 3). 이로 미루어보 아 대부분의 환자들이 수술 후 해당 부위 통증으로 인해 식사하는데 불편함을 느낀다는 것을 알 수 있었다. 또한 영양음료를 섭취하지 않은 대조군에서 식사 하는데 불편 함이 사라지는 기간을 설문한 결과, 술 후 7일 째부터 더 이상 불편함을 느끼지 않는 것으로 나타났다(Table 4).

\section{2. 술 후 식사 관련}

설문지 분석 결과, 실험군과 대조군 모두에서 부드러 운 음식 위주로 먹었다는 답변이 $46.7 \%$ 로 가장 많았다. 하지만 영양음료를 섭취한 실험군에서는 정상적으로 식 사를 하였다는 답변이 $31.4 \%$ 를 차지 하였다(Table 5). 또 한 영양음료 외에 치과 치료 후 영양 보충을 위해 섭취한 음식이나 제품이 있는지에 대한 설문 결과, 63명은 따로 섭취를 하지 않았고 27 명은 섭취를 하였다고 답변하였다

Table 2. Answers of respondents to the question, "How much discomfort did you experience after the periodontal surgery during eating?"

\begin{tabular}{ccccccc}
\hline & $\begin{array}{c}\text { Reluctant to eat } \\
\text { on account of } \\
\text { acute discomfort }\end{array}$ & Difficult to eat & $\begin{array}{c}\text { Felt a little } \\
\text { uncomfortable } \\
\text { when eating }\end{array}$ & No discomfort & Eat in comfort & Sum \\
\hline Group 1 & 4 & 5 & 9 & 7 & 5 & 30 \\
Group 2 & 8 & 5 & 8 & 5 & 4 & 30 \\
No drink & 5 & 7 & 12 & 5 & 1 & 30 \\
\hline
\end{tabular}

Table 3. Answers of respondents to the question, "What is the reason you experienced discomfort after the periodontal surgery?"

\begin{tabular}{ccccccc}
\hline & $\begin{array}{c}\text { Pain on } \\
\text { surgical site }\end{array}$ & $\begin{array}{c}\text { Food impaction } \\
\text { on surgical site }\end{array}$ & $\begin{array}{c}\text { Have no } \\
\text { appetite }\end{array}$ & $\begin{array}{c}\text { Anxious about bad influence } \\
\text { on recovery of surgical site }\end{array}$ & $\begin{array}{c}\text { Etc. } \\
\text { Sum }\end{array}$ \\
\hline Group 1 & 15 & 3 & 3 & 4 & 5 & 1 \\
Group 2 & 15 & 3 & 5 & 8 & 26 & 30 \\
No drink & 9 & 7 & 0 & 5 & 29 \\
\hline
\end{tabular}

Table 4. Answers of respondents to the question, "How long did it take till you felt relief from the pain during eating?"

\begin{tabular}{cccccccccccccc}
\hline $\begin{array}{c}\text { The day of the } \\
\text { operation }\end{array}$ & $\begin{array}{c}1 \\
\text { day }\end{array}$ & $\begin{array}{c}2 \\
\text { days }\end{array}$ & $\begin{array}{c}3 \\
\text { days }\end{array}$ & $\begin{array}{c}4 \\
\text { days }\end{array}$ & $\begin{array}{c}5 \\
\text { days }\end{array}$ & $\begin{array}{c}6 \\
\text { days }\end{array}$ & $\begin{array}{c}7 \\
\text { days }\end{array}$ & $\begin{array}{c}9 \\
\text { days }\end{array}$ & $\begin{array}{c}10 \\
\text { days }\end{array}$ & $\begin{array}{c}\text { Still } \\
\text { days }\end{array}$ & $\begin{array}{c}\text { Sum } \\
\text { persisting }\end{array}$ \\
\hline No drink & 4 & 4 & 3 & 6 & 3 & 3 & 0 & 5 & 0 & 0 & 1 & 1 & 30 \\
\hline
\end{tabular}


Table 5. Answers of respondents to the question, "How did you eat food after the periodontal surgery?"

\begin{tabular}{cccccccc}
\hline & $\begin{array}{c}\text { Normal diet } \\
\text { pattern }\end{array}$ & $\begin{array}{c}\text { Reduced } \\
\text { number of diet }\end{array}$ & $\begin{array}{c}\text { Reduced } \\
\text { amount of diet }\end{array}$ & $\begin{array}{c}\text { Soft food } \\
\text { primarily }\end{array}$ & $\begin{array}{c}\text { Drinks primarily } \\
\text { (Nutritional drinks } \\
\text { excepted) }\end{array}$ & Etc. \\
\hline Group 1 & 13 & 2 & 2 & 16 & 1 & 3 \\
Group 2 & 9 & 2 & 4 & 14 & 6 & 0 & 35 \\
No drink & 9 & 0 & 5 & 20 & 1 & 37 \\
\hline
\end{tabular}

Table 6. Answers of respondents to the question, "Have you intake any food or drinks to replenish nutrition after the periodontal surgery?"

\begin{tabular}{cccc}
\hline & Have intake & No intake & Sum \\
\hline Group 1 & 10 & 20 & 30 \\
Group 2 & 11 & 19 & 30 \\
No drink & 6 & 24 & 30 \\
\hline
\end{tabular}

Table 7. Answers of respondents to the question, "Do you think that nutritional drinks helped to recover your periodontal surgery?"

\begin{tabular}{lcccc}
\hline & Agree & Disagree & Not sure & Sum \\
\hline Group 1 & 16 & 1 & 13 & 30 \\
Group 2 & 20 & 0 & 10 & 30 \\
\hline
\end{tabular}

Table 8. Answers of respondents to the question, "If you think the drink helped recovery, what is the reason you feel It helped?"

\begin{tabular}{cccccc}
\hline & $\begin{array}{c}\text { Felt the wounds } \\
\text { heal up faster }\end{array}$ & $\begin{array}{c}\text { Helped regaining vigor } \\
\text { by solving hunger }\end{array}$ & $\begin{array}{c}\text { Relieved } \\
\text { the pain }\end{array}$ & $\begin{array}{c}\text { Nourished } \\
\text { sufficiently }\end{array}$ & Etc. \\
\hline Group 1 & 0 & 16 & 0 & 3 & 2 \\
Group 2 & 1 & 15 & 1 & 6 & 21 \\
\hline
\end{tabular}

Table 9. Answers of respondents to the question, "What is the appropriate daily dose of the drink you think?"

\begin{tabular}{cccccc}
\hline & $\begin{array}{c}\text { Less than 1 can } \\
\text { a day }\end{array}$ & $\begin{array}{c}1-2 \text { cans } \\
\text { a day }\end{array}$ & $\begin{array}{c}3-6 \text { cans } \\
\text { a day }\end{array}$ & $\begin{array}{c}\text { More than } 7 \text { cans } \\
\text { a day }\end{array}$ \\
\hline Group 1 & 2 & 12 & 14 & 2 & 30 \\
Group 2 & 0 & 6 & 19 & 2 & 27 \\
\hline
\end{tabular}

(Table 6). 따로 섭취한 음식의 예로는 죽, 비타민제, 영양 제, 옥수수불검화정량추출물, 칼슘제 등이 있었다. 이로 미루어보아, 환자 대부분은 해당 부위 통증으로 인해 부 드러운 음식 위주로 먹었고, 추가적인 영양보충을 위해 섭취한 제품 대부분이 저작이 필요 없는 부드러운 음식 이나, 알약 형태라는 것을 알 수 있었다.

\section{3. 영양음료 효과 분석}

영양음료를 섭취한 실험군 설문지 분석 결과, 영양음
료 섭취가 수술 후 회복에 도움이 되었다는 답변이 $60 \%$ 로 가장 많이 차지하였다(Table 7). 그 이유로는 공복감 을 해소하여 기력회복에 도움이 되었다는 답변이 $67.3 \%$ 로 가장 많았고 충분한 영양을 공급 받았기 때문에라는 답변이 $19.6 \%$ 로 두 번째로 많았다(Table 8). 이로 미루어 보아 영양음료 섭취로 인한 충분한 영양 공급이 환자의 기력을 회복하여 치유에 큰 도움을 준 것으로 사료된다. 또한 적정 일일 복용량에 관한 설문에서는 하루 3-6 캔 이 가장 많이 차지 하였다(Table 9). 


\section{고찰}

충분한 영양 공급은 환자의 기력 회복에 도움을 주어 수술 부위 치유에 큰 영향을 준다. 이점에 착안하여 최근 의료분야에선 영양음료 섭취를 적극적으로 도입하고 있 는데 당뇨, 고관절 골절 수술, 관상동맥 질환, 만성폐쇄성 폐질환 환자군에서 영양음료 섭취에 관한 임상적 효과를 다룬 논문들이 최근에 발표되고 있다. ${ }^{16-19}$ 더 나아가 의학 계에서는 수술 전 충분한 영양 섭취를 통하여 수술 중이 나 수술 후 생기는 합병증을 미리 막기 위한 접근법도 시 행 중이다. ${ }^{20}$

구강 영역을 치료하는 치과분야에서는 식사 동안 저작 활동이 수술 부위에 직접적인 악영향을 줄 수도 있으며 외과적 치주 치료 후 치아의 동요도 증가와 저작력 감소 로 인해 식사의 양과 질이 저하되고 그로 인해 영양섭취 부족으로 영양불량의 상태가 되거나 여러 질환이 나타날 수 있다. 이로 인한 심리적 불편감 또한 증가할 수 있지 만 안타깝게도 외과적 치주 치료 후 발생할 수 있는 식생 활과 영양 상태의 변화 및 저작력 및 구강 기능 만족도 변 화에 대한 연구는 거의 없는 실정이며, 특히 이러한 불편 감을 개선시켜 환자 삶의 질을 높이는 일환으로 영양보 충음료 공급이 갖는 효과에 대한 분석은 전무하다. 이에 본 연구에서는 외과적 치주 치료 후 식이보충을 위한 영 양음료 섭취 후 PROMs를 통한 환자 만족도를 조사하였 다.

술자가 판단하는 치료의 결과는 치료 자체의 임상적인 이점으로 연결될 수 있다. 그러나 환자의 관점은 치료 이 점에 대한 보다 더 전체적인 해석과 포괄적인 평가를 제 공할 수 있다. 예를 들어 치은연하소파술의 결과를 술자 가 판단할 때 치석과 주변 염증조직이 잘 제거되었고, 건 강한 치주결합조직의 재부착이 관찰되나 환자 스스로가 느끼기에 저작 시 불편하고 시린 증상이 있다면 이는 잘 된 치료라고 볼 수 없다. 따라서 치료 효과를 평가할 때, 임상적 결과와 환자 본인이 느끼는 만족감을 포함한 복 합적인 분석이 필수적이며 환자 중심의 접근 방식이 치료 및 관리의 종합적인 평가에 필수적이다. 따라서 임상에 있어 $\mathrm{PRO}$ 는 치료 결과에 대한 척도로써 우선적으로 고 려해야 할 일차적 결과 측정방법이 되야 할 것이다.

$\mathrm{PROMs}$ 는 초기에 약리학에서 환자의 임상 치료를 개 선하는 방법으로 사용하기 위해 개발 되었으며, 잉글랜 드, 스웨덴, 미국의 일부에 한정되었다. ${ }^{21}$ 하지만 이는 의 사 결정 중심에 환자를 배치함으로써 삶의 질과 안전성
을 증진시킬 뿐만 아니라 의료 변혁을 위한 가능성을 인 정받아 점차 임상 연구를 넘어서서 영역을 확장하고 있 다. 뿐만 아니라 PROMs는 술자가 아닌 환자가 직접 자 신의 만족도에 대해 측정하는 설문지로 치과 영역 뿐만 아니라 ${ }^{13,14}$ 의과, 과학, 패션 등 여러 분야에서 사용되며 중요성이 나날이 높아지고 있다.

본 연구에서 사용한 설문은 patient-reported outcome measures (PROMs)의 관점에서 저자가 특수 제작하였으 며 술 후 불편감과 영양음료 섭취를 통한 환자의 기능적 상태, 건강, 만족감 등을 조사하기 위한 항목으로 이루어 져있다. 설문 분석 결과, 영양음료가 수술 부위 회복에 도 움이 되었으며 그 결과 빠른 시일 내에 정상적인 식사를 할 수 있었다는 것을 알 수 있다. 수술 후 식사 시 불편함 의 원인으로는 통증, 붓기 등이 있는데, 영양음료 섭취는 수술 부위 자극이 적기 때문에 균형적인 영양 섭취가 가 능하고 이는 수술 후 회복에 큰 도움이 될 것으로 사료된 다. 또한 영양음료에는 환자에게 결핍되기 쉬운 비타민 C, 칼슘, 아연이 충분히 들어가 있는데, 아연 결핍 시 식 욕이 감퇴되고, 상처치유지연을 일으킬 수 있으므로 ${ }^{22}$ 이 를 미뤄 보아 영양음료를 통해 충분한 영양소를 섭취할 수 있고 이는 상처 치유에 큰 도움을 줄 것으로 사료된 다. 실험군, 대조군 모두 수술 후 부드러운 음식 위주로 먹었고, 영양음료 외 영양보충을 위해 따로 섭취한 음식, 영양소 대부분이 저작이 필요 없는 음식이나 알약 형태 였다. 이는 환자들이 수술 후 수술 부위에 자극을 피하고 싶어 하며 이에 따라 부드럽거나 바로 삼킬 수 있는 식사 를 원한다는 것을 알 수 있다.

이번 연구는 다음과 같은 한계를 가지고 있다. 첫째로 실험군, 대조군의 성별 비율과 평균 나이의 차이다. 이 는 식사 시 불편함 또는 수술 부위 회복에 대한 비교분석 에 제한점을 지닌다. 둘째로 치주 치료 종류에 따른 분석 의 한계이다. 이번 연구에서 행하여진 치주 치료는 발치, 치은판막소파술, 임플란트, advanced surgery가 있는데 advanced surgery에는 상악동 거상술, 골 이식술, 결합조 직이식술, 유리치은이식술이 포함되었다. 치주 치료에 따 른 회복 속도와 환자가 느끼는 통증은 다르기 때문에 영 양음료 섭취에 관한 만족도에 대해 절대적인 기준점을 정하는데 한계를 지닌다. 이를 극복하기 위해 더 나은 연 구방법의 모색과 동일한 수의 치주 수술, 절대적인 기준 점 등이 필요 할 것이다. 


\section{결론}

이번 연구에 따르면 외과적 치주 치료 후 영양음료를 섭취하였을 때 식사 대용 가능과 사용이 편리하다는 장 점이 확인되었다. 따라서 영양음료는 구강 내 수술로 인 한 식사의 불편함을 해결해줄 수 있는 효율적인 영양보 충제로 볼 수 있다. 또한 적절한 영양음료 섭취로 공복감 을 해소하고 충분한 영양공급을 받아 수술 후 회복에 큰 도움이 되었다는 설문 답변이 많았는데 이는 술 후 영양 공급과 심리적 안정이 필요한 상황에서 영양음료가 술 후 치유에 큰 도움이 될 것으로 사료된다. 이러한 측면에 서 술 후 영양공급을 위한 영양음료는 환자에게 육체적, 심리적으로 안정감을 줄 수 있는 좋은 치료 후 만족제로 볼 수 있을 것이며 향후 치과 내에서 적극적인 도입이 필 요할 것으로 사료된다.

\section{Acknowledgements}

본 연구는 대상주식회사의 지원으로 시행되었고 영양 음료(뉴케어)는 동회사에서 제공받았음.

\section{ORCID}

Jung-Chul Park http://orcid.org/0000-0002-2041-8047 Hyun-Seung Shin http://orcid.org/0000-0002-14109731

In-Woo Cho http://orcid.org/0000-0003-4985-3816

Hyeong-Seok Kim http://orcid.org/0000-0002-59624235

\section{References}

1. Amarasena N, Ogawa H, Yoshihara A, Hanada N, Miyazaki H. Serum vitamin C-periodontal relationship in community-dwelling elderly Japanese. J Clin Periodontol 2005;32:93-7.

2. Muñoz CA, Kiger RD, Stephens JA, Kim J, Wilson AC. Effects of a nutritional supplement on periodontal status. Compend Contin Educ Dent 2001;22:425-8, 430, 432 passim; quiz 440.

3. Rondanelli M, Opizzi A, Bonisio A, Lingua S, Cena H, Giacosa A, Roggi C. Nutritional management of patients suffering of chronic renal failure. Minerva
Urol Nefrol 2005;57:33-45.

4. Blendis LM. Nutritional management of patients with chronic liver disease. Baillieres Clin Gastroenterol 1989;3:91-108.

5. Lee J, Park JC, Jung UW, Choi SH, Cho KS, Park YK, Kim CS. Improvement in periodontal healing after periodontal surgery supported by nutritional supplement drinks. J Periodontal Implant Sci 2014;44:109-17.

6. Jenzsch A, Eick S, Rassoul F, Purschwitz R, Jentsch $H$. Nutritional intervention in patients with periodontal disease: clinical, immunological and microbiological variables during 12 months. Br J Nutr 2009;101:879-85.

7. Choi YK, Do SR, Park DY. Change in number of outpatients with periodontal diseases during recent 20 years based on patient survey. J Korean Acad Oral Health 2011;35:331-9.

8. Kim YI, Heo HY. A analysis on the patient's awareness of periodontal diseases. J Korean Soc Dent Hyg 2008;8:107-14.

9. Canakçi CF, Canakçi V. Pain experienced by patients undergoing different periodontal therapies. J Am Dent Assoc 2007;138:1563-73.

10. Fleszar TJ, Knowles JW, Morrison EC, Burgett FG, Nissle RR, Ramfjord SP. Tooth mobility and periodontal therapy. J Clin Periodontol 1980;7:495-505.

11. Feller L, Lemmer J. Tooth mobility after periodontal surgery. SADJ 2004;59:407, 409-11.

12. Ader DN. Developing the patient-reported outcomes measurement information system (PROMIS). Med Care 2007;45 Suppl 1:S1-S2.

13. McGrath C, Lam O, Lang N. An evidence-based review of patient-reported outcome measures in dental implant research among dentate subjects. J Clin Periodontol 2012;39 Suppl 12:193-201.

14. Rosen EB, Donoff RB, Riedy CA. U.S. dental school Deans' views on the value of patient-reported outcome measures in dentistry. J Dent Educ 2016;80:721-5.

15. Weldring T, Smith SM. Patient-reported outcomes (PROs) and patient-reported outcome measures (PROMs). Health Serv Insights 2013;6:61-8.

16. Li L, Yang M, Li Z, Yan X, Guo H, Pan H, Liu H, Liao Y, Yang G. Efficacy and safety of mitiglinide 
versus nateglinide in newly diagnose patients with type 2 diabetes mellitus: a randomized double blind trial. Diabetes Obes Metab 2012;14:187-9.

17. Botella-Carretero JI, Iglesias B, Balsa JA, Zamarrón I, Arrieta F, Vázquez C. Effects of oral nutritional supplements in normally nourished or mildly undernourished geriatric patients after surgery for hip fracture: a randomized clinical trial. JPEN J Parenter Enteral Nutr 2008;32:120-8.

18. Das UN. Nutritional factors in the prevention and management of coronary artery disease and heart failure. Nutrition 2015;31:283-91.
19. Mallampalli A. Nutritional management of the patient with chronic obstructive pulmonary disease. Nutr Clin Pract 2004;19:550-6.

20. Chang WB, Jung K, Ahn SH, Oh HG, Yoon MO. Pilot study for safety and efficacy of newly developed oral carbohydrate-rich solution administration in adult surgery patients. J Clin Nutr 2016;8:24-8.

21. Black N, Jenkinson C. Measuring patients' experiences and outcomes. BMJ 2009;339:b2495.

22. Lee EW, Lee YH, Paik HY, Heo DS. Effects of nutritional supplementation on nutritional status of cancer patients. Korean J Nutr 1997;30:177-86. 


\section{외과적 치주 치료 후 식이보충을 위한 영양음료 섭취에 관한 patient-reported outcome measures (PROMs) 조사}

\section{김형석 ${ }^{1}$, 조인우 ${ }^{1}$, 신현승 ${ }^{1}$, 박정철 ${ }^{1}, 2 *$}

${ }^{1}$ 단국대학교 치과대학 치주과학교실

${ }^{2}$ 이스트만 치과병원

목적: 외과적 치주 치료 후 해당 부위 통증과 불편감으로 인해 환자들은 제대로 된 식사가 불가능하며 따라서 적절한 영 양 섭취의 어려움으로 인해 삶의 질이 현저히 감소한다. 이에 본 연구에서는 외과적 치주 치료 후 환자의 적절한 영양 섭 취를 위해 일정 치유 기간 동안 영양음료를 나누어 마시게 하고 이에 대한 환자의 만족도를 분석하고자 한다.

연구 재료 및 방법: 외과적 치주 치료를 시행하고 기존에 시판되고 있는 영양음료를 임의의 섭취법에 따라 2개의 실험군 으로 나누어 마시게 하고 영양음료를 마시지 않는 대조군을 설정하여 총 90 명의 환자에게 영양음료 복용에 대한 환자의 만족도를 patient-reported outcome measures (PROMs)를 통하여 분석하였다.

결과: PROMs를 통한 분석 결과, 외과적 치주 치료 후 영양음료를 섭취하였을 때 식사 대용 가능과 사용이 편리하다는 장 점이 확인되었다. 또한 공복감을 해소하고 충분한 영양공급을 받아 수술 후 회복에 큰 도움이 되었다는 것이 확인되었다. 결론: 영양음료는 구강 내 수술로 인한 식사의 불편함을 해결해줄 수 있는 효율적인 영양보충제로 사료된다. 또한 술 후 영양 공급과 심리적 안정이 필요한 상황에서 영양음료가 술 후 치유에 큰 도움이 될 것으로 사료된다.

(구강회복응용과학지 2016;32(3):176-83)

주요어: 외과적 치주 치료; 영양섭취; PROMs; 창상 치유

*교신저자: 박정철

(31116)충남 천안시 동남구 단대로 119 단국대학교 치과대학 치주과학교실

Tel: 041-550-0261 || Fax: 303-3442-7364 | E-mail: jcp@dent.dku.edu

접수일: 2016년 8월 19일 | 수정일: 2016년 9월 12일 | 채택일: 2016년 9월 13일 